\title{
A Comparative Study Between Epoxy S-Glass UD And Epoxy Carbon UD For Their Use As Manufacturing Materials For Wind Turbine Blades
}

\author{
Hasan Nazha ${ }^{\text {a,* }}$, Zain Aldeen Nazha ${ }^{\mathrm{b}}$ \\ ${ }^{a}$ Faculty of Technical Engineering, University of Tartous, Tartous, Syria \\ ${ }^{b}$ Faculty of Mechanical and Electrical Engineering, Damascus University, Damascus, Syria
}

Received: 24 March 2020; Accepted: 03 May 2020; Published: 08 June 2020

\begin{abstract}
The majority of failure cases may occur because of the wrong selection of inappropriate material in the manufacture of wind turbine blades. Composites are used to increase reliability and reduce wind turbine manufacturing costs. Therefore, this research focuses on comparing the use of Epoxy S-Glass UD and Epoxy Carbon UD as manufacturing materials for wind turbine blades using 3D finite element analysis; to find out which of these materials have the best performance for its use as a manufacturing material for wind turbine blades. The distribution of Von Mises stresses in wind turbine blade models was investigated using Epoxy SGlass UD and Epoxy Carbon UD under the wind loads that affect the blade of the turbine. The results showed that the value of the maximum stresses in the epoxy glass model was $3.495 \times 107 \mathrm{~Pa}$, while this value was in the epoxy carbon model $4.0494 \times 107 \mathrm{~Pa}$. As for the value of the minimum stresses, it was in the epoxy glass model 7431.8 $\mathrm{Pa}$, while the value in another material model $17323 \mathrm{~Pa}$. Therefore, it is not recommended to use Epoxy Carbon UD as a manufacturing material for wind turbine blades, but it is recommended to use Epoxy SGlass UD, which reduces induced stresses and thus to prolong its lifespan.
\end{abstract}

Index Terms: Wind turbine; Composite materials; Epoxy; Glass fiber; Carbon fiber; Finite element analysis..

(C) 2020 Published by MECS Publisher. Selection and/or peer review under responsibility of the Research Association of Modern Education and Computer Science

* Corresponding author.

E-mail address: Hasannazha15@gmail.com 


\section{Introduction}

The growth of the renewable energy sector is growing rapidly in the world, dedicated to increasing the trend towards reducing dependence on fossil fuels [1]. Among the various sources of this renewable energy, there is the wind, which is a clean, free and available source everywhere in the world [2, 3]. Large wind turbines are widely used around the world to convert wind energy into curved motion [4]; it is then supplied either with a generator or to operate machinery directly for purposes such as grinding grain, pumping water, etc. [5].

According to statistics published by the World Wind Energy Association (WWEA), the total capacity of all installed wind turbines worldwide was 597 [GW] by the end of 2018. Hence the importance of reliance on wind turbines in renewable energy generation [6].

Turbine blades are the most important component of wind turbines, where achieving durability, light weight, resistance to wind loads and reducing gravity loads affect them are among the most important challenges facing engineers working in the renewable energy sector [7,8]. Consequently, composites are used to meet most of these requirements, increase reliability and reduce wind turbine manufacturing costs, as well as being environmentally friendly and recyclable $[9,10]$.

The finite element method has been used in many researches. Patel et al. [11] and El Chazly [12] used finite element analysis to predict static and dynamic performance of wind turbine blades. Kong et al. [13] studied the fatigue lifetime of Epoxy E-Glass wind turbine blades by performing a 3D finite element analysis. Bazilevs et al. [14] conducted a three-dimensional modeling of air movement around a wind turbine rotors and their impact on the structure of blades manufactured from Epoxy E-Glass.

In literature, many types of materials has been analyzed for using in manufacturing of wind turbine blades [15-18]. To our knowledge, this is the first investigation that focuses the comparison between the use of Epoxy S-Glass UD and Epoxy Carbon UD as manufacturing materials for wind turbine blades using 3D finite element analysis. The essential importance of this research is to overcome the majority of failure cases that may occur because of the wrong selection of inappropriate material in the manufacture of wind turbine blades by studying the stress distribution in wind turbine blades using 3D finite element analysis. Therefore, the aim of this research is to find out the composite material that has the best performance for its use as a manufacturing material for wind turbine blades.

\section{Materials and Methods}

\subsection{Modeling and meshing}

The 3D model was established using Autodesk ${ }^{\circledR}$ InventorTM software as shown in Figure 1.a for a wind turbine blade structure with a length of $10000 \mathrm{~mm}$. The diameter and length of the hub are $800 \mathrm{~mm}$ and 1500 $\mathrm{mm}$, respectively. The root and tip chord length are $1480 \mathrm{~mm}$ and $500 \mathrm{~mm}$ respectively as shown in Figure 1.b. The model was then exported to the ANSYSTM software to perform the finite element analysis (FEA).

Tetrahedron elements are used in the finite element analysis. The mesh consisted of 24871 nodes and 13017 elements as shown in Figure 2.a. The mesh is refined and accepted when the relative errors are less than 1\% to ensure the accuracy of the analysis. Therefore, this mesh consists of 125214 nodes and 461654 elements as shown in Figure 2.b.

\subsection{Boundary conditions}

The boundary conditions are defined as wind speed $(\mathrm{V}=10 \mathrm{~m} / \mathrm{s})$, the rotor diameter of the wind turbine $(\mathrm{D}=$ $20 \mathrm{~m})$ and air density $(\rho=1.29 \mathrm{Kg} / \mathrm{m} 3)$. Applying the equation (1) to calculate the forces acting on the turbine blade, we could find the following: 
$\mathrm{F}=\pi \times \rho \times \mathrm{V}^{2} \times \mathrm{D}^{2} / 9$

$\mathrm{F}=162024 / 9 \approx 18003 ? \mathrm{~N}$

These forces affect the surface of the flap and the edge of the blade as shown in Figure 3. The studied model has been fixed at the hub area as shown in Figure 3.

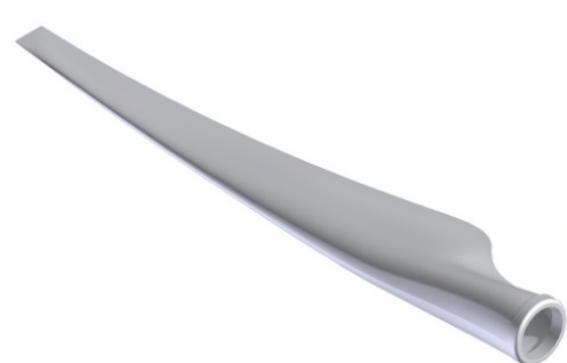

(a)

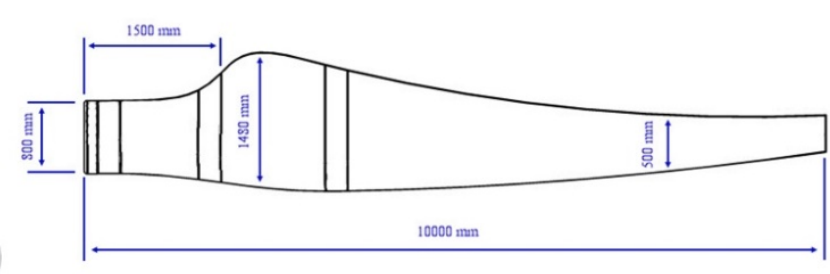

(b)

Fig. 1. The studied model: (a) 3D CAD model of the wind turbine blade, (b) the dimensions of the wind turbine blade

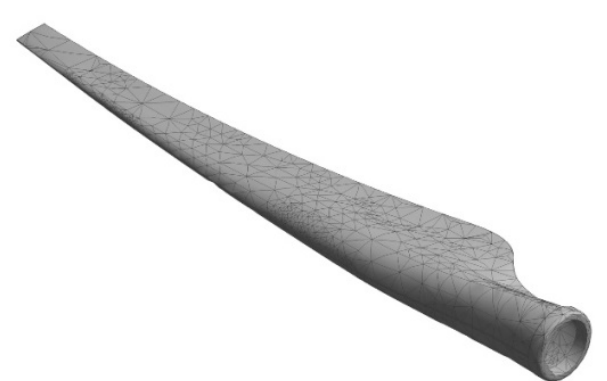

(a)

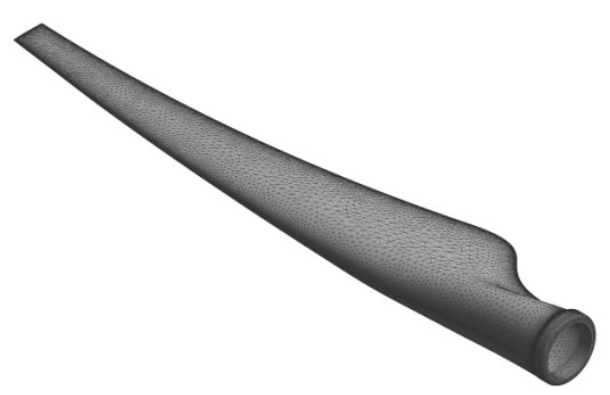

(b)

Fig. 2. 3D Mesh: (a) before refining, (b) after refining 


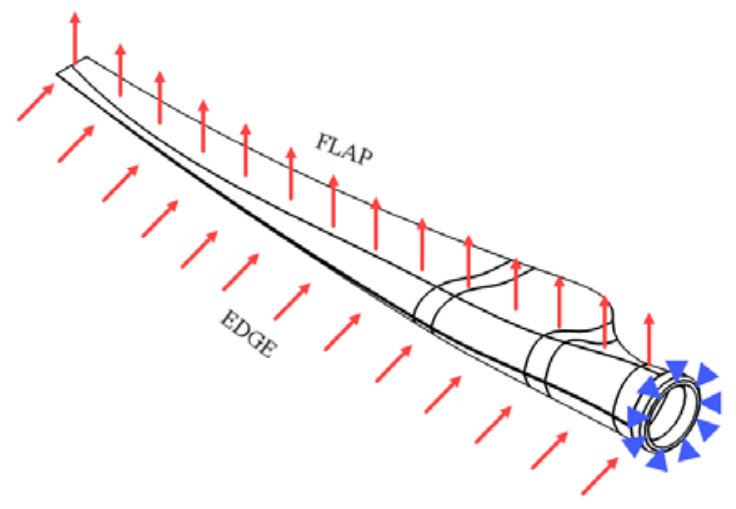

Fig. 3. Boundary conditions

\subsection{Material properties}

In the present study, the two composite materials were considered an orthotropic taking into consideration that the orthotropic materials do not have uniform mechanical properties in every direction [19]. The fiber plies in Epoxy S-Glass UD and Epoxy Carbon UD are orientated multidirectional and alternated with fiber orientations of 0 and 90 degrees as shown in Figure 4. Table 1 shows a summary of the mechanical properties of Epoxy S-Glass UD and Epoxy Carbon UD composite materials.

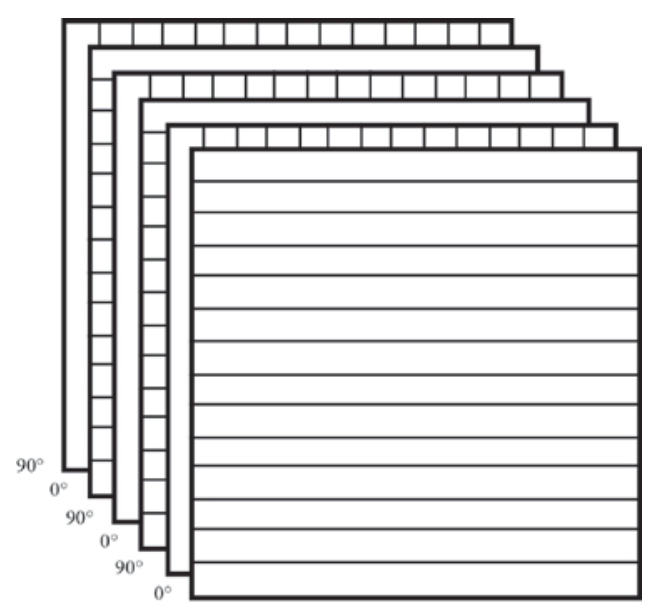

Fig. 4. Ply orientation of composite materials used in this study 
Table 1. Mechanical properties of composite materials used in this study

\begin{tabular}{|c|c|c|c|c|}
\hline Composite material & Plane & $\begin{array}{c}\text { Elastic modulus } \\
E[\mathrm{GPa}]\end{array}$ & $\begin{array}{c}\text { Shear modulus } \\
G[\mathrm{GPa}]\end{array}$ & $\begin{array}{c}\text { Poisson's ratio } \\
v\end{array}$ \\
\hline \multirow[t]{6}{*}{ Epoxy S-Glass UD } & $\mathrm{xx}$ & 50 & - & - \\
\hline & yy & 8 & - & - \\
\hline & $\mathrm{zz}$ & 8 & - & - \\
\hline & xy & - & 5 & 0.3 \\
\hline & $\mathrm{yz}$ & - & 3.84 & 0.4 \\
\hline & $\mathrm{xz}$ & - & 5 & 0.3 \\
\hline \multirow[t]{6}{*}{ Epoxy Carbon UD } & $\mathrm{xx}$ & 209 & - & - \\
\hline & yy & 9.45 & - & - \\
\hline & $\mathrm{zz}$ & 9.45 & - & - \\
\hline & xy & - & 5.5 & 0.27 \\
\hline & yz & - & 3.9 & 0.4 \\
\hline & $\mathrm{xz}$ & - & 5.5 & 0.27 \\
\hline
\end{tabular}

\section{Results and Discussions}

The data obtained from the finite element analysis can be presented in a stress distribution map with a color scale, which makes it possible to directly compare the magnitude and distribution of stress of various models. These results demonstrate the relationship between the stress distribution in the structure of the wind turbine blade and the materials of the studied models.

One of the theories most used to determine the stress is von Mises theory [20, 21]. Since the von Mises stress is a combination of normal and shear stresses occurring in all directions [22], it is important to investigate it in the structure of the wind turbine blade. Therefore, this theory has been applied to determine the stress distribution in the structure of the wind turbine blade using both Epoxy S-Glass UD and Epoxy Carbon UD composite materials.

From Figure 5, it is observed that the maximum stresses are concentrated at the hub area of wind turbine blade, and that the area of maximum stress distribution in the Epoxy Carbon UD model (Figure 5.b) is greater than in the Epoxy S-Glass UD model (Figure 5.a).

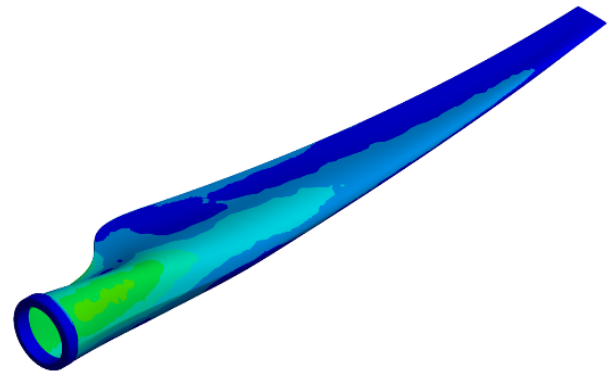

(a)

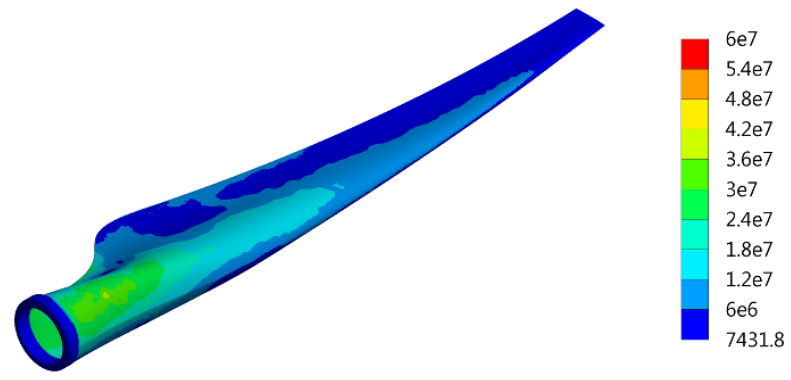

(b)

Fig. 5. Distribution of the stress in the studied models: (a) Epoxy S-Glass UD model, (b) Epoxy Carbon UD model

Table 2 shows the numerical results of the minimum and maximum values of von Mises stresses obtained as a result of the applied loads defined in the boundary conditions. The maximum stress in the Epoxy S-Glass UD 
model was $3.459 \times 107 \mathrm{~Pa}$, while it was $4.0494 \times 107 \mathrm{~Pa}$ in the Epoxy Carbon UD model. The minimum stress value was 7431.8 Pa in the Epoxy S-Glass UD model, while in the other model it was $17323 \mathrm{~Pa}$.

Table 2. Numerical results of minimum and maximum von Mises stress values in the studied models

\begin{tabular}{ccc}
\hline Composite material & Maximum stress & Minimum stress \\
\hline Epoxy S-Glass UD & $3.459 \times 10^{7}$ & 7431.8 \\
\hline Epoxy Carbon UD & $4.0494 \times 10^{7}$ & 17323 \\
\hline
\end{tabular}

By comparing the values of the maximum and minimum stresses resulting from the analysis taking into account the maximum tensile strength values of each material (Epoxy S-Glass UD $=475 \times 107 \mathrm{~Pa}$, Epoxy Carbon UD $=290 \times 107 \mathrm{~Pa}$ ), Epoxy S-Glass UD composite material shows better performance for using as a manufacturing material for wind turbine blades.

The forces that the wind turbine blades are affected by vary between the pressure forces and the tensile forces; in addition, there are the shear forces that these blades are affected by. Therefore, the use of a composite material such as Epoxy S-Glass UD could help to distribute and dampen wind loads applied to the turbine blades, resulting in low-value and unconcentrated stresses at a specific area, which improves the durability of the wind turbine blade structure.

No earlier studies have compared Epoxy S-Glass UD and Epoxy Carbon UD for their use as manufacturing materials for wind turbine blades. However, comparison of current results to prior studies may be instructive. Seidel et al. [23] noted that great stresses are concentrated in the region of the wind turbine blade hub, Park [24] also referred to the same result, which is in agreement with the presented results in this study.

Some limitations remain in this study and must be taken into consideration in the model in order to optimize computational resources without affecting the essential analysis. Given that the proposed concept is based on structural analysis, further research is required to perform computational fluid dynamics (CFD) and modal analysis of wind turbine blade to compare different composites for their use as manufacturing materials for wind turbine blades.

Nevertheless, as mentioned, the Epoxy S-Glass UD model presents a better mechanical behavior than other one. It can efficiently distribute the applied load and present more homogeneous behavior of stress distribution than the Epoxy Carbon UD model. That will enhance the durability of wind turbine blade and prolong its lifespan.

\section{Conclusions}

This study compared, using 3D-FEA, the Epoxy S-Glass UD and Epoxy Carbon UD composites for their use as manufacturing materials for wind turbine blades; to find out which of these materials have the best performance. The Epoxy S-Glass UD model presents a better mechanical behavior than other one. It can efficiently distribute the applied load and present more homogeneous behaviour of stress distribution than the Epoxy Carbon UD model, which will enhance the durability of wind turbine blade and prolong its lifespan. Further investigations of performing computational fluid dynamics (CFD) and modal analysis of wind turbine blade to compare different composites are required to achieve a better understanding of their behavior.

\section{Acknowledgements}

The authors would like to thank William Abbas (Faculty of Mechanical Engineering, Czech Technical University, Prague, Czech Republic) for his support. 


\section{References}

[1] Purwono, B., M., Setiawan, A., Subali Patma, T., Bagus Suardika, I. (2017). The strategy of simulation effects of wind speed, variation of turbine blades and it's interaction to power generated by vertical axis wind turbine using NACA 2412. International Journal of Engineering \& Technology, 7(1.2), 246-250. http://doi.org/10.14419/ijet.v7i1.2.9314

[2] Wong, K. H., Chong, W. T., Poh, S. C., Shiah, Y. C., Sukiman, N. L., Wang, C. T. (2018). 3D CFD simulation and parametric study of a flat plate deflector for vertical axis wind turbine. Renewable energy, 129, 32-55. https://doi.org/10.1016/j.renene.2018.05.085

[3] Albi, Dev Anand, M., M. Joselin Herbert, G. (2018). Aerodynamic Analysis on Wind Turbine Aerofoil. International Journal of Engineering \& Technology, 7(3.27), 456-465. http://doi.org/10.14419/ijet.v7i3.27.17997

[4] Khudri Johari, M., Azim A Jalil, M., Faizal Mohd Shariff, M. (2018). Comparison of horizontal axis wind turbine (HAWT) and vertical axis wind turbine (VAWT). International Journal of Engineering \& Technology, 7(4.13), 74-80. http://doi.org/10.14419/ijet.v7i4.13.21333

[5] Spera, D. A. (2009). Wind turbine technology: fundamental concepts of wind turbine Engineering, Second Edition. New York: ASME press. 1- 832. https://doi.org/10.1115/1.802601

[6] Panduranga, R., Alamoudi, Y., Ferrah, A. (2019). Nanoengineered Composite Materials for Wind Turbine Blades. In 2019 Advances in Science and Engineering Technology International Conferences (ASET) (pp. 1-7). IEEE. https://doi.org/10.1109/ICASET.2019.8714217

[7] Author Kong, C., Bang, J., Sugiyama, Y. (2005). Structural investigation of composite wind turbine blade considering various load cases and fatigue life. Energy, 30(11-12), 2101-2114. https://doi.org/10.1016/j.energy.2004.08.016

[8] Benham, A., Thyagarajan, K., John Sylvester, J., Prakash, S. "Structural Analysis of a Wind Turbine Blade", Advanced Materials Research, Vol. 768, pp. 40-46, 2013. https://doi.org/10.4028/www.scientific.net/AMR.768.40

[9] Song, F., Ni, Y., \& Tan, Z. (2011). Optimization design, modeling and dynamic analysis for composite wind turbine blade. Procedia Engineering, 16, 369-375. https://doi.org/10.1016/j.proeng.2011.08.1097

[10] Cousins, D. S., Suzuki, Y., Murray, R. E., Samaniuk, J. R., \& Stebner, A. P. (2019). Recycling glass fiber thermoplastic composites from wind turbine blades. Journal of cleaner production, 209, 1252-1263. https://doi.org/10.1016/j.jclepro.2018.10.286

[11] Patel, M. H., \& Garrad, A. D. (1990). The development of a finite element method for the dynamic analysis of wind turbines. In 12th British Wind Energy Association Conf (p. 315-318).

[12] El Chazly, N. M. (1993). Static and dynamic analysis of wind turbine blades using the finite element method. Renewable Energy, 3(6-7), 705-724. https://doi.org/10.1016/0960-1481(93)90078-U

[13] Kong, C., Kim, T., Han, D., \& Sugiyama, Y. (2006). Investigation of fatigue life for a medium scale composite wind turbine blade. International journal of Fatigue, 28(10), 1382-1388. https://doi.org/10.1016/j.jfatigue.2006.02.034

[14] Bazilevs, Y., Hsu, M. C., Kiendl, J., Wüchner, R., \& Bletzinger, K. U. (2011). 3D simulation of wind turbine rotors at full scale. Part II: Fluid-structure interaction modeling with composite blades. International Journal for numerical methods in fluids, 65(1 - 3), 236-253. https://doi.org/10.1002/fld.2454

[15] Brøndsted, P., Lilholt, H., \& Lystrup, A. (2005). Composite materials for wind power turbine blades. Annu. Rev. Mater. Res., 35, 505-538. https://doi.org/10.1146/annurev.matsci.35.100303.110641

[16] Thomsen, O. T. (2009). Sandwich materials for wind turbine blades-present and future. Journal of Sandwich Structures \& Materials, 11(1), 7-26. https://doi.org/10.1177/1099636208099710

[17] Mishnaevsky Jr, L., Brøndsted, P., Nijssen, R., Lekou, D. J., \& Philippidis, T. P. (2012). Materials of large wind turbine blades: recent results in testing and modeling. Wind Energy, 15(1), 83-97. 
https://doi.org/10.1002/we.470

[18] Mishnaevsky, L., Branner, K., Petersen, H. N., Beauson, J., McGugan, M., \& Sørensen, B. F. (2017). Materials for wind turbine blades: an overview. Materials, 10(11), 1285. https://doi.org/10.3390/ma10111285

[19] Darwich, A., Nazha, H., \& Abbas, W. (2019). Numerical study of stress shielding evaluation of hip implant stems coated with composite (carbon/PEEK) and polymeric (PEEK) coating materials. Biomedical Research, 30(1), 169-174. https://doi.org/10.35841/biomedicalresearch.30-18-1048

[20] Lanting, Z. (2012). Research on structural lay-up optimum design of composite wind turbine blade. Energy Procedia, 14, 637-642. https://doi.org/10.1016/j.egypro.2011.12.988

[21] Oganesyan, P., Zhilyaev, I., Shevtsov, S., \& Wu, J. K. (2016). Optimized design of the wind Turbine’s composite blade to flatten the stress distribution in the mounting areas. In The Latest Methods of Construction Design (pp. 335-341). https://doi.org/10.1007/978-3-319-22762-7_50

[22] Beer, F. P., Johnston, E. R. (1981) Mechanics of materials. New York: McGraw-Hill, 616 pp.

[23] Seidel, C., Jayaram, S., Kunkel, L., \& Mackowski, A. (2017). Structural Analysis of Biologically Inspired Small Wind Turbine Blades. International Journal of Mechanical and Materials Engineering, 12(1), 19. https://doi.org/10.1186/s40712-017-0085-3

[24] Park, H. (2017). Structural Design and Analysis of Wind Turbine Blade with Skin-Spar-Sandwich Composite Structure. DEStech Transactions on Engineering and Technology Research, (apetc 2017), 2056-2060. https://doi.org/10.12783/dtetr/apetc2017/11425 


\section{Authors' Profiles}

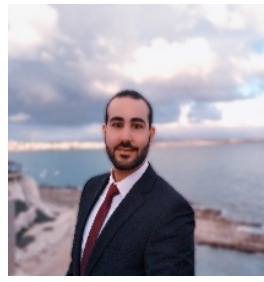

Hasan Nazha PhD candidate, Faculty of Technical Engineering, University of Tartous, Tartous, Syria. Passionate about scientific research, especially in the field of applied materials engineering, I have published 6 research papers in international journals and 2 research papers in national journals.

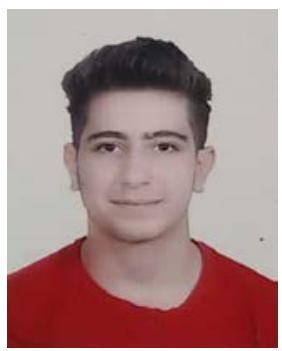

Zain Aldeen Nazha Student, Faculty of Mechanical and Electrical Engineering, Damascus University, Damascus, Syria. Projects-Computational applications in different fields of technology.

How to cite this paper: Hasan Nazha, Zain Aldeen Nazha," A Comparative Study Between Epoxy S-Glass UD And Epoxy Carbon UD For Their Use As Manufacturing Materials For Wind Turbine Blades", International Journal of Mathematical Sciences and Computing(IJMSC), Vol.6, No.3, pp.33-41, 2020. DOI: 10.5815/ijmsc.2020.03.04 